\title{
Stress dependency and unloading-induced swelling behaviour of a high plasticity overconsolidated clay of Paleogene origin
}

\author{
Emil Mejlhede Kinslev ${ }^{1,2, *}$, Ole Hededal ${ }^{2}$, Irene Rocchi ${ }^{1}$, Varvara Zania ${ }^{1}$ \\ ${ }^{1}$ Danish University of Technology, Civil engineering Department, 2800 Kgs. Lyngby, Denmark \\ ${ }^{2} \mathrm{COWI}$ A/S, Marine and foundation engineering Department, $2800 \mathrm{Kgs}$. Lyngby, Denmark
}

\begin{abstract}
High plasticity clay of Paleogene origin in Denmark, possess unique deformational behaviour with significant stress dependent stiffness in oedometric loading/unloading. This is challenging settlement/heave predictions. The behaviour has been so far associated with high smectite content and complex geological loading history. Burial followed by erosion and then glaciotectonic activity, has resulted in fissures and slickensides, along with a high level of overconsolidation. Several currently planned and existing Danish construction projects encounter problems with such clays. Specifically, the immersed tunnel project connecting Denmark and Germany: "Fehmarn Fixed Link", for which an extensive laboratory campaign of IL and CRS oedometer tests, has been carried out. These tests have been re-analysed, to obtain a better description of the swelling behaviour of Paleogene clays, due to the net unloading state expected for this immersed tunnel. The development of the swelling index during unloading, although non-linear, tends to reach a constant value at sufficient stress reduction. This constant value as well as the average swelling index increases with the stress at which unloading starts and increased smectite content. These trends are confirmed by an additional CRS test.
\end{abstract}

\section{Introduction}

Designing for the serviceability limit state requires an adequate representation of the deformational behaviour, for the soil influencing the construction. One soil type that poses a design challenge to currently planned projects in Denmark, is high plasticity clay of Paleogene origin, due to its nonlinear and hysteretic behaviour in oedometric loading and unloading. Existing projects built in this soil type, like the old Little Belt Bridge, have encountered problems, when settlements significantly exceeding the predictions occurred after construction. Based on Incremental Loading (IL) 1D consolidation tests on clay from this site, Hansen and Mise [1] proposed a theory describing the shape of the unloading-reloading branches as closed hysteretic loops of hyperbolic shape. The curvature of the loops were governed by the geological preconsolidation. This framework has so far been the common practice for describing deformational behaviour of Danish high plasticity Paleogene clays. But, in currently planned Danish projects, such as the Fehmarn Fixed Link, there are strict requirements in the precision and accuracy of the settlement/heave estimation. Therefore, it is imperative that the deformational behaviour of Paleogene clays is adequately defined and described.
"High plasticity Paleogene clays" is a common term used for the series of formations from the Eocene epoch in the Danish region, named by Heilmann-Clausen [2]: the Røsnæs Clay, the Lillebælt Clay and the Søvind Marl. These formations, which consist mainly of clay, contain considerable amounts of smectite and have undergone a complex loading history.

The sedimentation of these formations occurred at a time when the North Sea covered the current onshore Denmark, i.e. in an ocean of several hundred meters depth, well below the wave base. Consequently, the sediments reaching this location comprised primarily of clay particles. The deposition occurred over a period of several million years, at an approximate rate of $1 \mathrm{~mm} / 100$ years, similar to that witnessed nowadays for deep ocean deposits. The deposition of these clays occurred after a period of large volcanic activity in the Icelandic Hotspot. The active clay mineral smectite was produced from weathering of the volcanic ash, and makes up a significant part of the clays mineral composition. As the source of smectite was eventually diminished, its content in the clay decreases with decreasing age of the deposit [3]. Usually an opposite trend occurs since smectite tends to transform into illite with time. This process though, only takes place when water and potassium $(\mathrm{K})$ is present. A very low permeability along

\footnotetext{
* Corresponding author: emki@byg.dtu.dk and emkv@,cowi.com
} 
with too little potassium naturally available, did not allow the completion of this transformation [3].

Following this long period with a stable depositional environment, several other formations from the late Paleogene and Neogene period were deposited on top of the high plasticity Paleogene clays. Due to changes in the global sea level during the Neogene, a series of exposures and re-immersions with consequent erosion and deposition, took place in Denmark. All this lead to deposition and then erosion of a net 250-1000 meters of material above the high plasticity Paleogene clays, depending on the geographical position in Denmark [4]. The high plasticity Paleogene clays (beneath this eroded soil) therefore experienced both a high loading and subsequent unloading, from burial and erosion.

In the Quaternary period glaciotectonic activity lead to remoulding of the Paleogene clays through large thrust fault structures with folded parts, slickensides and micro fissures [5].

\subsection{The Fehmarn Fixed Link project}

The Fehmarn Fixed Link is a project designed to construct a fixed connection between Denmark and Germany. The chosen solution is an immersed tunnel at the alignment shown in Figure 1. The Fehmarn Fixed Link project provides an opportunity for the study of Danish high plasticity Paleogene clays since these clays are present at the tunnel alignment and therefore challenge the prediction of settlement/heave. The dredging for the tunnel is planned to start in 2020. Following this, the tunnel elements along with rock fill will be installed. Due to the lower weight of the installed construction, compared to the excavated soil, the foundation soil is in a net unloading state at the completion of the project.

An extensive geotechnical investigation was carried out in 2009-2010, to be used for the tendering phase when both a bridge and a tunnel solution were still considered for the construction of the link. Data and material became available for commercial as well as for scientific study.

The geotechnical investigation consisted of an extensive boring campaign with 36 offshore and 12 onshore borehole locations, where high-quality piston samples $(\varnothing 101 \mathrm{~mm})$ were retrieved. The boreholes reach a maximum depth of

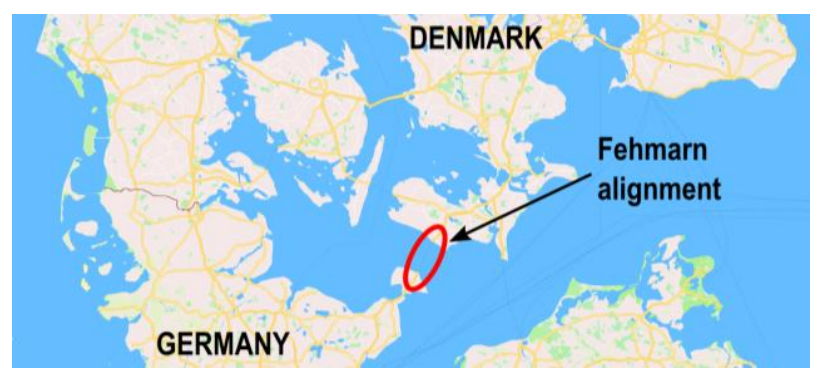

Fig. 1. Overview of the alignment of the Fehmarn Fixed Link, modified from Google maps.

100 meters below surface, penetrating well into the Paleogene formations, which begin between 5 and 75 meters below ground level (i.e. seabed) along the alignment [6].

The Røsnæs Clay at the Fehmarn alignment is divided into two parts denoted "folded" and "intact", describing whether it was subjected to disturbance from glaciotectonic activity or not. The boundary between the folded and intact clay, lies between 35 and 75 meters below seabed. The folded Røsnæs Clay received the most attention due to its location at shallow depth and thus in the zone relevant for the deformations of the tunnel. On the folded part of the Røsnæs Clay, the laboratory program consists of 68 Incremental Loading (IL) and 13 Constant Rate of Strain (CRS) 1D-consolidation tests.

\section{Methodology}

The results from the geotechnical investigations are collected in a database owned by Femern A/S; access to the database was granted to the authors and soil cores for further testing were provided. Femern A/S ([6], [7]) presents an overview of tests performed on Paleogene clay, along with interpretations of the experiments performed. The IL and CRS tests on Paleogene clay comply with [8] and [9] respectively. The general testing strategy describes loading to a low estimate of the preconsolidation pressure, followed by unloading. From this state, either reloading or further unloading was performed, to simulate stress paths corresponding to either a bridge or a tunnel construction.

In order to minimise osmotic swelling the performed tests used water of similar salt composition $\left(\mathrm{Cl}^{-}, \mathrm{SO}_{4}{ }^{2-}\right.$, $\mathrm{Na}^{+}, \mathrm{K}^{+}, \mathrm{Mg}^{2+}$ and $\mathrm{Ca}^{2+}$ ) and $\mathrm{pH}$ to that leached from 18 samples evenly distributed along the alignment. Some variations in the strain rate for the CRS tests exists. In loading, the rates span from $0.01 \% / \mathrm{hr}$ to $0.08 \% / \mathrm{hr}$, with no tests exceeding a pore pressure ratio of $15 \%$. In unloading, they span from $0.01 \% / \mathrm{hr}$ to $0.55 \% / \mathrm{hr}$. The pore pressure ratio in unloading exceeds $15 \%$ due to low effective stresses at the end of the step. The lowest reached pore pressure ratio in unloading is $-120 \%$ with the second lowest being $-42 \%$. No consistent difference was observed between the unloading branches at low and high strain rates in terms of shape and location in the $\left(\sigma^{\prime}{ }_{\mathrm{v}}-\mathrm{e}\right)$ plane and values of derived parameters.

A series of IL and CRS test data were retrieved from the Femern database and the unloading induced swelling behaviour of the folded Røsnæs Clay was re-analysed. The interpretations by Femern A/S ([6], [7]), of the timecurves for the individual load steps in the IL tests, were reassessed. New interpretations were made in a few cases, where inconsistency in the interpretation of single load steps was found. From these tests a total of 72 IL and 11 CRS unloading branches were available for this study. The original reporting relied on volumetric strains to describe the deformation of the samples. For a more consistent comparison of the different tests, the reported strains were converted to void ratios. Since void ratio is expected to represent the state of the soil to a larger extent, and therefore its load history.

An additional CRS test was performed in a setup with a closed cell, where the sample was installed directly in 
the cutting ring. A backpressure of $140 \mathrm{kPa}$ was applied, and the entire loading and unloading were carried out with a strain rate of $0.05 \% / \mathrm{hr}$. In loading the pore pressure ratio never exceeded $10 \%$, while in unloading $80 \%$ was reached at the end of the unloading branch. A relaxation phase was carried out in the transition between loading and unloading.

Multiple classification parameters (i.e. mineralogy, specific surface area, grain density, clay content, carbon content, consistency limits and index, initial water content and void ratio) were determined for a more detailed soil characterization. The development of $\mathrm{C}_{\mathrm{s}}$ (both tangential, and secant from start of unloading) was plotted against: $\mathrm{w}_{0}, \mathrm{e}_{0}$, e at start of unloading $\left(\mathrm{e}_{\mathrm{u}}\right), \sigma_{\mathrm{v} 0}, \mathrm{w}_{\mathrm{L}}, \mathrm{w}_{\mathrm{P}}, \mathrm{IP}, \mathrm{CaCO}_{3}$, CC, SC and SSA. Possible correlations and trends with combinations of the parameters, in linear and log scales were investigated. Liquid limit $\left(\mathrm{w}_{\mathrm{L}}\right)$ and smectite content (SC) were found as the best correlating parameters, among the abovementioned set. The liquid limit $\left(\mathrm{w}_{\mathrm{L}}\right)$ was determined with the falling cone [10], while the SC was estimated from XRD results.

\section{Results}

The reported classification data from Femern A/S [6] for the folded part of the Røsnæs Clay, is summarised in Table 1.

Tab. 1. Classification parameters for folded Røsnæs Clay. Smectite content is of the clay fraction

\begin{tabular}{|c|c|c|}
\hline Parameter & Unit & Value \\
\hline grain density $\left(\rho_{\mathrm{s}}\right)$ & $\mathrm{g} / \mathrm{cm}^{3}$ & $2.68-2.87$ \\
\hline initial bulk density $\left(\rho_{0}\right)$ & $\mathrm{g} / \mathrm{cm}^{3}$ & $1.75-1.98$ \\
\hline initial water content $\left(\mathrm{w}_{0}\right)$ & $\%$ & $29-43$ \\
\hline initial void ratio $\left(\mathrm{e}_{0}\right)$ & - & $0.85-1.18$ \\
\hline liquid limit $\left(\mathrm{w}_{\mathrm{L}}\right)$ & $\%$ & $98-198$ \\
\hline plasticity limit $\left(\mathrm{w}_{\mathrm{P}}\right)$ & $\%$ & $14-48$ \\
\hline plasticity index $(\mathrm{IP})$ & $\%$ & $58-168$ \\
\hline carbon content $(\mathrm{CaCO})$ & $\%$ & $1-7$ \\
\hline clay content $(<2 \mu \mathrm{m})(\mathrm{CC})$ & $\%$ & $53-89$ \\
\hline smectite content $(\mathrm{SC})$ & $\%$ & $18-75$ \\
\hline specific surface area $(\mathrm{SSA})$ & $\mathrm{m}^{2} / \mathrm{g}$ & $58-68$ \\
\hline
\end{tabular}

As it can be concluded from Table 1, the folded Røsnæs Clay is not as homogenous as is generally reported in geological literature, see Section 1. Particularly noticeable are $\mathrm{w}_{\mathrm{L}}$ and IP, which span more than $100 \%$. Due to the large subjectivity in the measurement of $\mathrm{WP}_{\mathrm{P}}$ (thus also influencing IP), and less in the measurement of $\mathrm{w}_{\mathrm{L}}$, the latter is deemed a more reliable parameter for identifying trends among the different test results. The liquid limit $\left(\mathrm{w}_{\mathrm{L}}\right)$ can be linked to $\mathrm{SC}$ as it is shown in Figure 2. A general linear trend between the two parameters seems to exist, though with some scatter and outliers. Figure 2 shows previously reported correlations, summarised by Paykov and Hawley [11] along with the correlation by Lodahl [12] who studied mixtures of

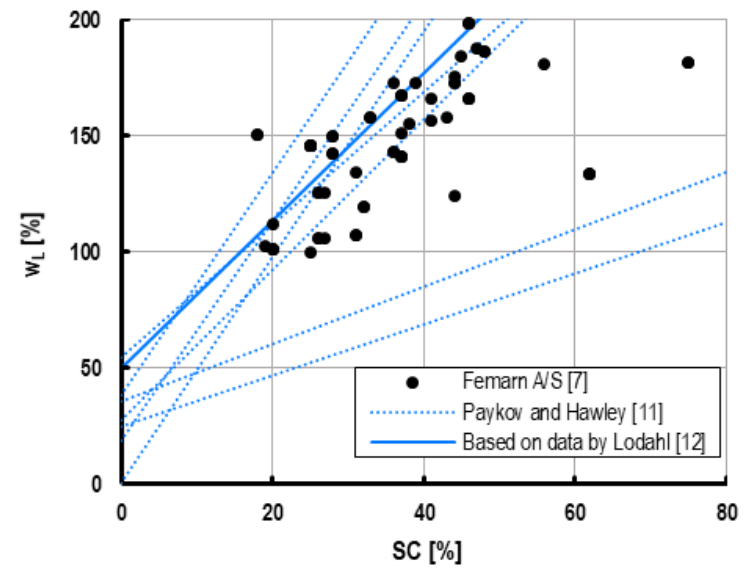

Fig. 2. Comparison of $\mathrm{SC}$ and $\mathrm{w}_{\mathrm{L}}$ for all oedometer samples, along with previous reported correlations.

kaolinite and bentonite, thus with controlled mineralogy.

After conversion to void ratio (instead of strain) the unloading branches sorted by SC are illustrated in Figure 3. As can be seen from Figure 3, the unloading branches span across a rather wide range of void ratios and stresses. The general shape of the unloading branches is non-linear starting with a low swelling index $\left(\mathrm{C}_{\mathrm{s}}=\Delta \mathrm{e} / \log \left(\sigma^{{ }^{\prime}}{ }_{1} / \sigma^{\prime}{ }_{2}\right)\right)$ that increases for increased unloading. For a few tests, $\mathrm{C}_{\mathrm{s}}$ decreases again at low stresses (i.e. below 50-250 kPa). The development of $\mathrm{C}_{\mathrm{s}}$ during unloading is better represented when plotting it against the Unloading Index $\left(\mathrm{UI}=\sigma^{\prime}{ }_{\mathrm{v}, \mathrm{u}} / \sigma^{\prime}{ }_{\mathrm{v}}\right.$, where $\sigma^{\prime}{ }_{\mathrm{v}, \mathrm{u}}$ is the stress at which unloading started). Figure 4 confirms the general trend of increasing $\mathrm{C}_{\mathrm{s}}$ with increased unloading seen in Figure 3. It may be further observed, that $\mathrm{C}_{\mathrm{s}}$ for many of the tests seems to reach a plateau, i.e. an upper bound value. The value of $C_{s}$ at this plateau is denoted as the swelling index yield $\left(\mathrm{C}_{\mathrm{s}, \mathrm{y}}\right)$. For some of the tests, $\mathrm{C}_{\mathrm{s}}$ decreases again at higher UI, as also shown in Figure 3. The swelling index yield $\left(\mathrm{C}_{\mathrm{s}, \mathrm{y}}\right)$ is reached at UI between 1.5 and 7.2. No trend has here so far been found in the initial increase of $C_{s}$ until $C_{s, y}$. In order to elaborate on the observed trend of $\mathrm{C}_{\mathrm{s}, \mathrm{y}}$, this value was determined for each test, where

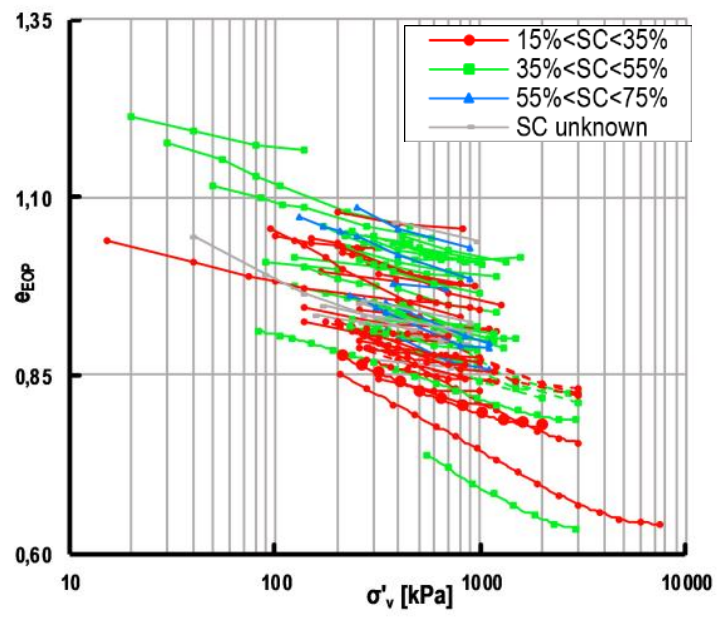

Fig. 3. All unloading branches, sorted by SC. Dashed lines indicate second and third unloading branches in the same test. The additional test is highlighted by larger symbols. 


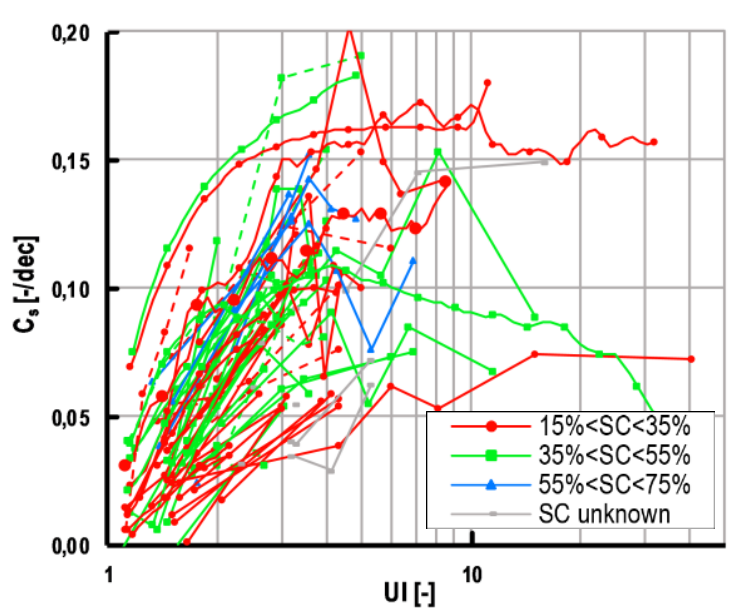

Fig. 4. Development of $\mathrm{C}_{\mathrm{s}}$ with UI, sorted by SC. Dashed lines indicate second and third unloading branches in the same test. The additional test is highlighted by larger symbols.

possible, and plotted against $\sigma_{\mathrm{v}, \mathrm{u}}$. Figure 5 shows a general trend of $C_{s, y}$ increasing with $\sigma_{v, u}^{\prime}$, with the additional CRS fitting well with this trend. The trend is clearer when looking only at the tests which reach $\mathrm{C}_{\mathrm{s}, \mathrm{y}}$ at low UI (black). A tendency of lower SC giving lower $\mathrm{C}_{\mathrm{s}, \mathrm{y}}$, may also be seen in Figure 5. Again the trend is most particularly pronounced when looking only at the tests which reach $\mathrm{C}_{\mathrm{s}, \mathrm{y}}$ at low UI. Figure 5 only gives information about the plateau, therefore another way of plotting the curves that gives similar information, but keeps the shape of the entire curve, is explored.

By comparing the unloading branches to the CamClay framework, which has constant $\mathrm{C}_{\mathrm{s}}$ (and therefore linear parallel unloading branches in the $\left(\log \left(\sigma_{v}^{\prime}\right), e\right)$-plane), the deviation from linearity can be observed. To show the difference consistently a proper normalisation is needed. In realising that the development of void ratio on an unloading branch can be described through Equation 1 .

$$
\begin{gathered}
e-e_{u}=C_{s}\left(\log \left(\sigma^{\prime}{ }_{v, u}\right)-\log \left(\sigma^{\prime}{ }_{v}\right)\right) \\
\Delta e=C_{s} \log (U I)
\end{gathered}
$$

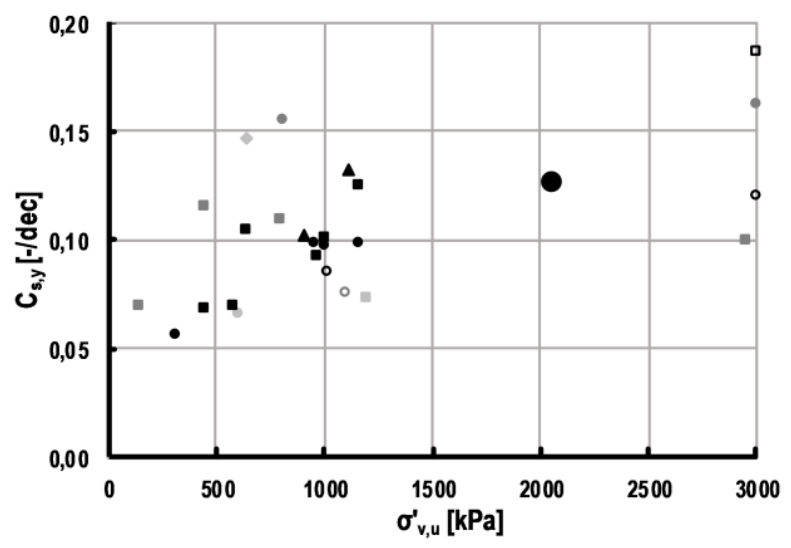

Fig. 5. Development of $C_{s, y}$ with the $\sigma^{\prime}{ }_{v, u}$, sorted by SC and UI at which $\mathrm{C}_{\mathrm{s}, \mathrm{y}}$ is reached. SC: (Circle): $15-35 \%$, (Square): $35-$ $55 \%$, (Triangle): $55-75 \%$, (Diamond): not determined. UI: (Black): 1.5-3.4, (Dark grey): 3.4-5.3, (Light grey): 5.3-7.2. Empty points indicate second and third unloading branches in the same test. The additional test is highlighted by a larger symbol. where $\left(\sigma^{\prime}{ }_{v, u}, e_{u}\right)$ is the state at which unloading starts and $\left(\sigma^{\prime}, e\right)$ is the state on the unloading branch at some unloading. It can be seen from Equation 1 that all unloading branches will plot as the same line in a $(\log (U I), \Delta e)$-plane under the assumption of constant $\mathrm{C}_{\mathrm{s}}$. This plot can therefore be used to identify the variation from a constant $C_{\mathrm{s}}$. Figure 6 and 7 present these correlations grouped by the $\mathrm{e}_{\mathrm{u}}$ and $\sigma_{\mathrm{v}, \mathrm{u}}$, and sorted with $\mathrm{w}_{\mathrm{L}}$ and $\mathrm{SC}$ respectively. Since $\mathrm{e}_{\mathrm{u}}$ and $\mathrm{w}_{\mathrm{L}}$ are not perfectly correlated to $\sigma_{\mathrm{v}, \mathrm{u}}$ and $\mathrm{SC}$ respectively, a deviation between Figure 6 and 7 is observed. Figures 5, 6 and 7 confirm the observations from Figure 3, i.e. that the general shape of the unloading branches is non-linear starting with a high stiffness that gradually decreases. For most tests, to a constant value, as also seen in Figure 4. Additionally, the general trend of a higher $\mathrm{C}_{\mathrm{s}, \mathrm{y}}$ with higher $\sigma_{\mathrm{v}, \mathrm{u}}\left(\right.$ or lower $\mathrm{e}_{\mathrm{u}}$ ), as seen in Figure 5, is observed as well. This trend is more pronounced when grouping the tests with stress, compared to void ratio (comparing Figures 7 and 6).

The trend of increased $\mathrm{C}_{\mathrm{s}, \mathrm{y}}$ with $\mathrm{SC}$, shown in Figure 5 , is also seen in Figure 7. Figure 6 (where sorting is by $\mathrm{w}_{\mathrm{L}}$ ) does not show a trend of $\mathrm{C}_{\mathrm{s}, \mathrm{y}}$ increasing with $\mathrm{w}_{\mathrm{L}}$ clearly. Therefore (despite the link between $\mathrm{W}_{\mathrm{L}}$ and SC shown in Figure 2), SC is the dominating parameter for the sorting. Neither of the trends (increased $\mathrm{C}_{\mathrm{s}, \mathrm{y}}$ with increased $\sigma_{\mathrm{v}, \mathrm{u}}$ and SC) are very significant, but still visible, which suggests that better or more state or classification parameters are needed to capture the observed phenomena.

\section{Discussion}

The transitioning of $\mathrm{C}_{\mathrm{s}}$ into a constant value (in this paper termed $\mathrm{C}_{\mathrm{s}, \mathrm{y}}$ ) has been observed by several other authors: Femern A/S [7] recognised the presence of the unloading branches transitioning into a plateau of constant $C_{s}$, but in terms of swelling ratio ( $\mathrm{Q}_{\mathrm{un}}$ ). A common value of 4-8 $\% /$ dec was suggested for the Røsnæs, Ølst and Holmehus formations. Krogsbøll et al. [13] reported observations of $\mathrm{C}_{\mathrm{s}}$ transitioning into a plateau for an IL test on Lillebælt Clay. This test started with a low index of $\mathrm{C}_{\mathrm{s}}<0.05$ increasing to a plateau of $\mathrm{C}_{\mathrm{s}, \mathrm{y}}=0.12$ in the first two unloading loops. In the final unloading $\mathrm{C}_{\mathrm{s}}$ increased to $\mathrm{C}_{\mathrm{s}, \mathrm{y}}=0.2$. The explanation given by Krogsbøll et al. [13] for the increase in $\mathrm{C}_{\mathrm{s}, \mathrm{y}}$ was that destructuration of the sample caused by repeated unloading and reloading occurred. Rocchi et al. [14] conducted a series of IL tests on both folded and intact Røsnæs Clay from the Fehmarn alignment. For the intact Røsnæs Clay unloading was carried out to UI $>100$, in which case $\mathrm{C}_{\mathrm{s}}$ first reached a peak at 0.17 and 0.16 for deionised and saline water respectively, both at $\mathrm{UI}=3.5$. From that peak $\mathrm{C}_{\mathrm{s}}$ steadily decreased again.

Rocchi et al. [14] did not find a constant $C_{s}$ for the folded Røsnæs Clay. Either the unloading was carried out to UI up to 2 , in which case for the first unloading, $\mathrm{C}_{\mathrm{s}}$ increased from 0.01 to 0.03 , and in the consecutive unloadings it increased from 0.03 to 0.07 , without a clear trend of reaching a plateau. The increasing $\mathrm{C}_{\mathrm{s}}$ for consecutive unloading loops complies with the 
observations by Krogsbøll et al. [13], though in this case with the significant difference between the first and following loops. The reason for the lack of a plateau (e.g. in Rocchi et al. [14] tests on folded Røsnæs Clay) can be explained by the low UI. Gasparre and Coop's [15] data for London Clay, shows a trend of overall increased steepness of the unloading branches with increased $\sigma_{\mathrm{v}, \mathrm{u}}$.
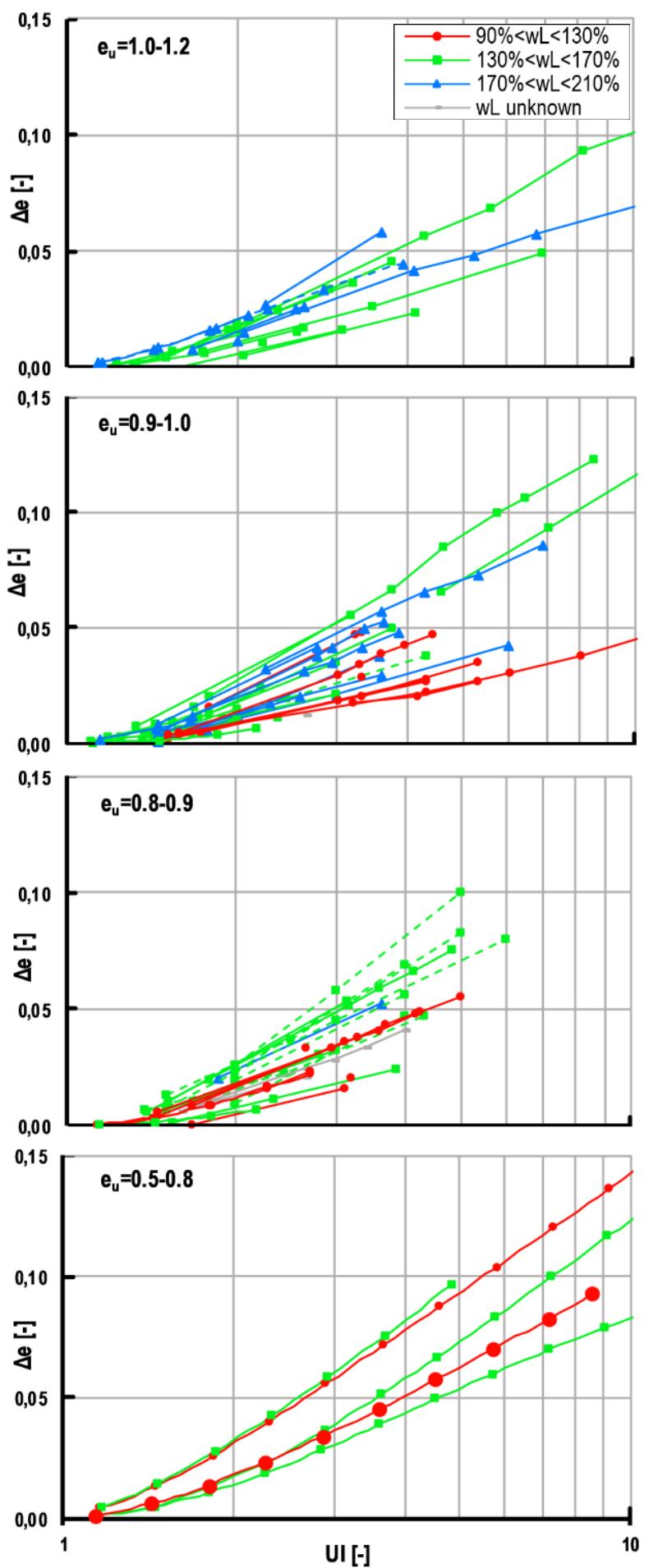

Fig. 6. Change in void ratio with $\log (\mathrm{UI})$, sorted by $\mathrm{w}_{\mathrm{L}}$. Dashed lines indicate second and third unloading branches in the same test. The additional test is highlighted by larger symbols.
They describe this increase to be an effect of destructuration of the sample, from loading to a high stress level. Thus, two explanations exists: 1) destructuration is caused by repeated unloading and reloading or, 2) from loading to a high stress level.
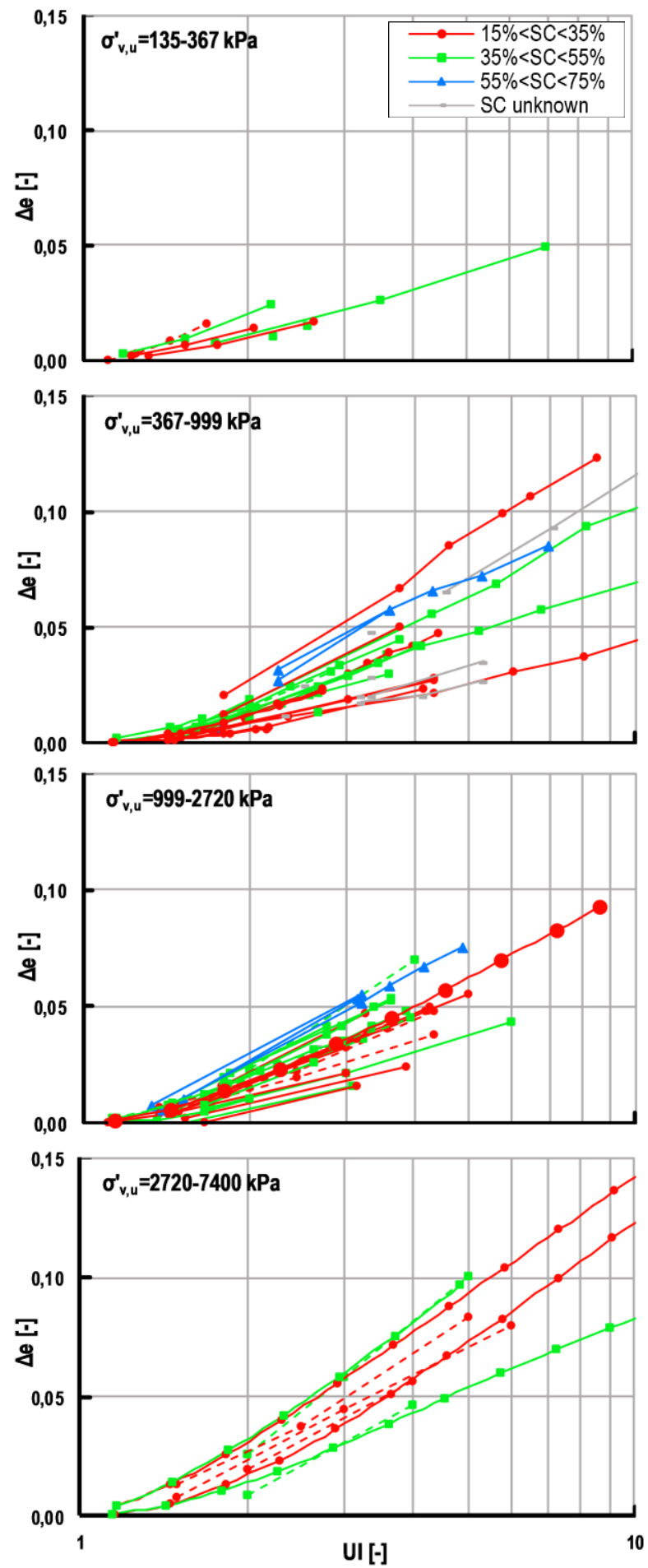

Fig. 7. Change in void ratio with $\log (\mathrm{UI})$, sorted by SC. Dashed lines indicate second and third unloading branches in the same test. The additional test is highlighted by larger symbols. 
Both hypotheses can apply to the results from [13], [14] and [15]. Therefore, further testing is needed to clarify the dominant destructuration process.

Lodahl [12] conducted IL tests on artificial mixtures of kaolinite and bentonite and did not find any effect of consecutive unloading, as suggested by Krogsbøll et al. [13] and Rocchi et al. [14]. These tests continued to UI as high as 20 , but did not transition into a constant $\mathrm{C}_{\mathrm{s}}$. Decrease of curvature was observed though. Since Lodahl's [12] samples were reconstituted and therefore had no structure, destructuration could not occur, which complies with the hypotheses presented by Krogsbøll et al. [13] and Gasparre and Coop [15]. Further, these tests indicate that the transition of $\mathrm{C}_{\mathrm{s}}$ into $\mathrm{C}_{\mathrm{s}, \mathrm{y}}$ may be an effect of structure. In Lodahl's [12] artificial samples the SC varied between 0 and $65 \%$. He found that increased SC leads to higher $\mathrm{C}_{\mathrm{s}}$ (defined in [12] as the secant value for the entire unloading reloading loop) backing up the trend from Figures 5 and 7. In Lodahl's [12] tests, the scatter in $\mathrm{C}_{\mathrm{s}}$ increased with increasing $\mathrm{SC}$, which may explain the high scatter in the trends for Røsnæs Clay due to a generally high SC. The observation of increasing $\mathrm{C}_{\mathrm{s}}$ with increased SC corresponds to the trends in Figure 7. Although not represented in the reported $\mathrm{C}_{\mathrm{s}}$ values, increasing $\mathrm{SC}$ increases the hysteresis of the unloading reloading loops in Lodahls tests [14]. Femern A/S [7] discarded the influence from SC on the swelling behaviour, due to lack of a trend when including the samples from the Holmehus formation, which have a higher SC (63-93\%). However, Femern A/S [7] did not investigate the combination of stress dependency and SC, which reveals this trend.

The observed decrease of $\mathrm{C}_{\mathrm{s}}$ at low stress and high UI for some tests in Figure 4, was also found by Krogsbøll et al. [13] for the last load step of the last unloading branch with a stress of $25 \mathrm{kPa}$ and UI $>90$. Rocchi et al. [14] also made a similar observation, for the intact samples, but with a more continuous decrease after the previously mentioned peak.

\section{Conclusion}

High plasticity Paleogene clay challenge settlement/heave predictions for the currently planned Fehmarn Fixed Link tunnel. To increase the knowledge of the general behaviour in unloading, the IL and CRS tests from the geotechnical investigation of the project were reanalysed. An additional CRS test was performed to validate and extend these trends.

The unloading behaviour of folded Røsnæs Clay is characterized by a general non-linear development in the $\left(\log \left(\sigma_{\mathrm{v}}\right), \mathrm{e}\right)$-plane as seen from the unloading branches. This non-linearity is more pronounced when using the Unloading Index and the change in void ratio.

$\mathrm{C}_{\mathrm{s}}$ was used as a parameter for describing the unloading behaviour. The general evolution of $\mathrm{C}_{\mathrm{s}}$ during an unloading branch is to start with an initial low value and increase with increased unloading. At sufficient unloading, $\mathrm{C}_{\mathrm{s}}$ reaches a constant value or plateau, which was termed $\mathrm{C}_{\mathrm{s}, \mathrm{y}}$. For the tests where unloading was continued to a very low stress, a subsequent decrease of
$\mathrm{C}_{\mathrm{s}}$ from $\mathrm{C}_{\mathrm{s}, \mathrm{y}}$ was observed. The value of $\mathrm{C}_{\mathrm{s}, \mathrm{y}}$ was found to increase with $\sigma_{\mathrm{v}, \mathrm{u}}$. The Unloading Index was used to define the amount of unloading in one branch. It was found that the trend of increased $\mathrm{C}_{\mathrm{s}, \mathrm{y}}$ with increased $\sigma_{\mathrm{v}, \mathrm{u}}$, is most significant for the test reaching $\mathrm{C}_{\mathrm{s}, \mathrm{y}}$ at low Unloading Index.

The average change in void ratio from unloading to similar UI increases with $\sigma^{\prime}{ }_{\mathrm{v}, \mathrm{u}}$ and smectite content. This is partly an effect of $\mathrm{C}_{\mathrm{s}, \mathrm{y}}$ increasing with $\sigma_{\mathrm{v}, \mathrm{u}}{ }^{\prime}$ and smectite content. The trend based on smectite content is secondary to the trend based on $\sigma_{\mathrm{v}, \mathrm{u}}$.

The observations contain scatter and some outliers from the trends. Therefore, better or more state or classification parameters are necessary to capture the observed phenomena. Using void ratio and liquid limit as alternatives to stress and smectite content for the description of the deformational behaviour in unloading neither reduced the scatter nor provided clearer trends.

Funding from Innovation Fund Denmark for the project 'Efficient performance of large infrastructure: a geomechanical approach towards sustainable design' - grant number 703800203B - is gratefully acknowledged. The authors express gratitude to Femern $\mathrm{A} / \mathrm{S}$ for providing the data and the soil samples.

\section{References}

1. J. B. Hansen, T. Mise, Bulletin DK Geo. Inst., 17, 513 (1964)

2. C. Heilmann-Clausen, O. B. Nielsen, F. Gersner, Bulletin Geo. Soc. DK, 33, 287-323 (1985)

3. O. B. Nielsen, E. S. Rasmussen, B. I. Thyberg, Jour. Sedi. Res., 85. 562-581 (2015)

4. O. Michelsen, Bulletin Geo. Soc. DK, 43, 9-21 (1996)

5. S. A. S. Pedersen, Geosciences, 4, 269-296 (2014)

6. Femern A/S. GDR 18.0-005 (2013)

7. Femern A/S. GDR 00.1-001 (2014)

8. ASTM D 2435-04 (2004)

9. ASTM D 4186-06 (2006)

10. CEN ISO/TS 17892-12 (2004)

11. O. Paykov, H. Hawley, App. Clay Sci., 104, 261-268 (2015)

12. M. R. Lodahl, Influence of smectite content on the deformation behaviour of clay (AU Library Scholarly Publishing Services, 2017)

13. A. Krogsbøll, O. Hededal, N. N. Foged, Proc. $16^{\text {th }}$ NGM, 1, 133-140 (2012)

14. I. Rocchi, G. di Remigio, G. L. Grønbech, V. Zania, Proc. Mic.-Mac. Math. Mod. Soil. Mech, (to be published)

15. A. Gasparre, M. R. Coop, Can. Geo. Jour., 45, 13241334 (2008) 